\title{
Diferentes técnicas de pulverização sobre o depósito de gotas na cultura do trigo
}

\section{Rafael de Souza Christovam ${ }^{1}$, Carlos Gilberto Raetano', Leonardo Aparecido Inacio Leite², Evandro Pereira Prado ${ }^{3}$, Mário Henrique Ferreira do Amaral Dal Pogetto ${ }^{4}$}

\author{
${ }^{1}$ Universidade Estadual Paulista “Júlio de Mesquita Filho”, Câmpus Botucatu, São Paulo, Brasil. E-mail: srchristovam@bol.com.br, \\ raetano@fca.unesp.br \\ ${ }^{2}$ JBS Biodiesel, Lins, São Paulo, Brasil. E-mail: inacioleite@gmail.com \\ ${ }^{3}$ Universidade Estadual Paulista “Júlio de Mesquita Filho”, Câmpus Dracena, São Paulo, Brasil. E-mail: epprado@ dracena.unesp.br \\ ${ }^{4}$ Dow AgroSciences, Crop Protection R\&D, São Paulo, SP, Brasil. E-mail: mfdalpogetto@dow.com
}

Recebido: 25/07/2017; Aceito: 19/01/2018

\section{RESUMO}

A cultura do trigo (Triticum aestivum L.), tem relevante importância no mundo. Ao longo dos tempos, com o surgimento de doenças, foram desenvolvidas pesquisas para buscar a melhor eficiência no controle desses patógenos. Para obter resultados de melhor eficiência em aplicação curativa de fungicidas, o presente trabalho objetivou avaliar técnicas de pulverização sobre o depósito de gotas nas folhas da cultura. Foram realizados dois experimentos na área experimental da FCA/UNESP - Campus de Botucatu, sendo divididos em duas áreas: área de agricultura e área cascalheira. No Experimento I utilizou-se o esquema fatorial $3 \times 2$, com quatro repetições; foram dispostos três níveis de ar $\left(0 ; 15 ; 29 \mathrm{~km} \mathrm{~h}^{-1}\right)$, dois volumes de pulverização $\left(100 \mathrm{~L} \mathrm{ha}^{-1}\right.$ e $\left.200 \mathrm{~L} \mathrm{ha}^{-1}\right)$. No Experimento II foram três níveis de ar $\left(0 ; 15 ; 29 \mathrm{~km} \mathrm{~h}^{-1}\right)$ e dois ângulos diferentes de inclinação das pontas de pulverização em relação a cultura $\left(0^{\circ}\right.$ e $\left.30^{\circ}\right)$. Nos estádios de segundo nó visível com 53 dias após semeadura (DAS) e emborrachamento completo 67 DAS foram realizadas pulverizações com fungicida triazol (tebuconazole). No Experimento I, na aplicação realizada aos 53 DAS, o tratamento com $200 \mathrm{~L} \mathrm{ha}^{-1} \operatorname{com~} 29 \mathrm{~km} \mathrm{~h}^{-1}$ foi mais eficiente, para o Experimento II o melhor resultado foi obtido aos 67 DAS com ângulo de $30^{\circ}$ e vento de $15 \mathrm{~km} \mathrm{~h}^{-1}$. Com base no estudo realizado torna-se possível alcançar melhor controle curativo dos patógenos que possam se instalar na cultura.

Palavras-chave: tecnologia de aplicação, assistência de ar, ângulo de pulverização.

\section{Different spraying techniques on the deposit of drops in wheat culture}

\begin{abstract}
Wheat (Triticum aestivum L.) has important importance in the world, with the appearance of diseases, there is also researching to seek the best efficiency in the control of these pathogens. To obtain better efficiency results in the curative application of fungicides, the present work aimed to evaluate spray techniques on the deposit of droplets on the leaves of the culture. Two experiments were carried out in the experimental area of FCA/UNESP - Campus de Botucatu, being divided into two areas: agriculture area and gravel area. Two experiments were performed in the $3 \times 2$ factorial scheme with four replicates in Experiment I: three air levels $\left(0 ; 15 ; 29 \mathrm{~km} \mathrm{~h}^{-1}\right)$, two spray volumes $\left(100 \mathrm{~L} \mathrm{ha}^{-1}\right.$ and $\left.200 \mathrm{~L} \mathrm{ha}^{-1}\right)$. In Experiment II, there were three levels of air $\left(0 ; 15 ; 29 \mathrm{~km} \mathrm{~h}^{-1}\right)$, and two different angles of inclination of the spray tips with respect to culture $\left(0^{\circ}\right.$ and $\left.30^{\circ}\right)$. In the second visible node stages with 53 days after sowing (DAS) and complete rubber production 67 DAS were sprayed with triazole fungicide (tebuconazole). In Experiment I, in the application to the 53 DAS, the treatment with $200 \mathrm{~L} \mathrm{ha}^{-1}$ with $29 \mathrm{~km} \mathrm{~h}^{-1}$ was more efficient, for Experiment II the best result was obtained in the 67 DAS with angle of $30^{\circ}$ and wind of $15 \mathrm{~km}$ $\mathrm{h}^{-1}$. Based on the study we can obtain better ways of curative control of the pathogens that may come to install in the crop.
\end{abstract}

Key words: application technology, air Assistance, spray angle. 


\section{Introdução}

A cultura do trigo (Triticum aestivum L.) é de grande relevância em todo mundo. $\mathrm{O}$ grão é formado por três partes: gérmen (rico em proteínas e lipídios), utilizado para ração animal; casca (rica em fibra, minerais e vitaminas) que se transforma em farelo; endosperma (amido) de onde se origina a farinha utilizada para panificação. O Brasil, um dos maiores produtores de grãos ainda não consegue suprir a necessidade do mercado interno com sua produção de trigo.

No Sul do Brasil, onde temos a maior produção nacional, o clima é muito instável, principalmente em relação à precipitação pluviométrica e temperatura. Esta região caracteriza-se pelo excesso hídrico e temperaturas altas durante o desenvolvimento dos cultivos de inverno contribuindo para a ocorrência e severidade de doenças, constituindo-se a principal causa da instabilidade das safras (NAVARINI; BALARDIN, 2012).

Essa produção pode ser afetada por vários fatores como doenças, as quais limitam ou comprometem a sua produção. As doenças que incidem na parte aérea, como as ferrugens, o oídio, as manchas foliares e da espiga podem causar prejuízos consideráveis, especialmente sob condições climáticas favoráveis ao desenvolvimento de epidemias (SANTOS et al, 2011).

Os prejuízos são agravados quando várias doenças incidem simultaneamente na lavoura. Dados sobre danos causados por doenças na cultura do trigo são bastante variáveis, especialmente porque diversos fatores interferem no estabelecimento e desenvolvimento das epidemias, tais como: condições ambientais, maior ou menor suscetibilidade das cultivares, agressividade dos patógenos e época do início da infecção.

Com a instalação da doença há perda de produção; para minimizar tal perda é necessário que se realize aplicações curativas com fungicidas para controle da doença, contudo não basta apenas se escolher o melhor fungicida mas também o equipamento utilizado para que ocorra deposição mínima de defensivo no alvo a ser controlado (SARI et al., 2014).

Observa-se vários estudos sobre a aplicação curativa de fungicidas na cultura do trigo, porém, apenas no que se refere às diferentes pontas de aplicação. Poucos estudos relatam sobre a eficiência com a diminuição de volume de calda (Fiallos et al., 2011). Na tentativa de minimizar perdas e melhorar a eficiência de controle de agentes nocivos à cultura do trigo, o presente trabalho teve por objetivo comparar os depósitos da pulverização, com dois modelos de pontas, em diferentes níveis de ar junto à barra, com dois volume de calda e ângulos de posicionamento das pontas.

\section{Material e Métodos}

Os experimentos na cultura do trigo cv. IAC-370 foram conduzidos na área experimental da fazenda de Ensino, Pesquisa e Produção (FEPP) da FCA/UNESP Campus de Botucatu, área didática do Departamento de Produção Vegetal, denominadas Agricultura e Cascalheira. A área de Agricultura está situada a 694 metros de altitude, sob as coordenadas geográficas $22^{\circ}$ $41^{\prime} 33,5^{\prime \prime}$ de latitude Sul e $48^{\circ} 25^{\prime} 22,7^{\prime \prime}$ de longitude Oeste, com vento predominante na direção Leste para Oeste. A área Cascalheira está situada a 724 metros de altitude, com as coordenadas geográficas $22^{\circ} 48^{\prime} 59,7^{\prime \prime}$ de latitude Sul e $48^{\circ} 25^{\prime} 38,2^{\prime \prime}$ de longitude Oeste, com vento predominante na direção Leste para Oeste.

A seleção do cultivar IAC-370, ocorreu pela sua adaptação na região de Botucatu-SP e ciclo de desenvolvimento médio 120 a 130 dias, proporcionando um tempo maior da cultura a campo.

Para a semeadura da cultura, utilizou-se o sistema de plantio direto, com espaçamento de $0,17 \mathrm{~m}$ entre linhas com 65 plantas por metro, $200 \mathrm{~kg} \mathrm{ha}^{-1}$ de adubo N P K (formula 8-28-16) e aos trinta dias após a germinação foi realizada adubação de cobertura com $100 \mathrm{~kg}$ ha ${ }^{1}$ uréia, fonte de nitrogênio. Adubações foram realizadas com base na análise de solo de ambas as áreas, atribuindo-se à elas a correção de solo exigida para a cultura.

Foram feitas duas aplicações fungicidas como controle curativo, nos estádios de desenvolvimento, 32 (segundo nó visível), aos 53 Dias Após Semeadura (DAS) e estádio 45 (emborrachamento completo), aos 67 DAS, com pontas de pulverização XR 110015 à100 $\mathrm{L} \mathrm{ha}^{-1}$ e XR 11003 à $200 \mathrm{~L} \mathrm{ha}^{-1}$, espaçadas de $0,50 \mathrm{~m} \mathrm{e}$ posicionadas a $0,50 \mathrm{~m}$ de altura do alvo. Para as aplicações foi utilizado fungicida com ingrediente ativo Tebuconazole $200 \mathrm{~g} / \mathrm{L}$, com dose de $0,6 \mathrm{~L} \mathrm{ha}^{-1}$ ou $120 \mathrm{~g}$ i.a $\mathrm{ha}^{-1}$, juntamente com o corante alimentício Azul Brilhante em solução aquosa $(0,15 \%)$. Para as aplicações o equipamento disponível para as aplicações foi o pulverizador de arrasto Advance Vortex 2000.

A velocidade de deslocamento do conjunto tratorpulverizador foi $7 \mathrm{~km} \mathrm{~h}^{-1}$. Optou-se pela ponta de jato plano XR 110015 e XR 11003 devido à compatibilidade da tecnologia utilizada com a estrutura do diâmetro mediano volumétrico (DMV) das gotas da pulverização; $198 \mu \mathrm{m}$ e $241 \mu \mathrm{m}$ respectivamente, e também ao volume de calda obtido na respectiva condição operacional. Durante a pulverização, as condições meteorológicas em ambas áreas estão apresentadas na Tabela 1.

Foram desenvolvidos dois experimentos distintos neste trabalho, sendo Velocidade do Ar x Volume de Calda e Velocidade do Ar x Ângulo de inserção das pontas de pulverização em relação à cultura, ambos desenvolvidos na Área da Agricultura e Cascalheira. 
Tabela 1: Condições meteorológicas na área de Agricultura no momento das aplicações

\begin{tabular}{ccccc}
\hline DAS & $\begin{array}{c}\text { Umidade } \\
\text { relativa do } \\
\operatorname{ar}(\%)\end{array}$ & $\begin{array}{c}\text { Temperatura } \\
\left({ }^{\circ} \mathrm{C}\right)\end{array}$ & $\begin{array}{c}\text { Velocidade } \\
\text { do vento } \\
\left(\mathrm{km} \mathrm{h}^{-1}\right)\end{array}$ & $\begin{array}{c}\text { Horário de } \\
\text { aplicação } \\
(\text { Horas })\end{array}$ \\
\hline 53 & $70-75$ & $19,5-21,2$ & $2,3-2,5$ & $8-10$ \\
\hline 67 & $68,3-69,5$ & $18,5-21$ & $5,5-7,5$ & $8-10$ \\
\hline
\end{tabular}

No Experimento I foi avaliado Velocidade do AR $\mathrm{x}$ Volume de calda conduzido no delineamento de blocos distribuídos no esquema fatorial 3 x 2 , três níveis de ar zero (sem ar), 15 e $29 \mathrm{~km}^{-1}$ (velocidade máxima da rotação do ventilador) combinados a dois volumes de aplicação 100 e $200 \mathrm{~L} \mathrm{ha}^{-1}$ com 4 repetições sendo parcelas de 8,0 x 10,0 m.

No Experimento II foi avaliado, Velocidade do AR x Ângulo de inserção das pontas de pulverização nas barras. Conduzido no delineamento de blocos no esquema fatorial $3 \times 2$, três níveis de ar zero (sem ar), 15 e $29 \mathrm{~km}^{-1}$, combinados a dois ângulos $0^{\circ}$ e $30^{\circ} \operatorname{com} 4$ repetições sendo parcelas de 8,0 x 10,0 metros.

Para avaliação de cada parcela foram selecionadas 20 plantas de trigo, cortadas rente ao solo, com auxílio de tesouras e colocadas, individualmente, em sacos plásticos devidamente identificados e acondicionados em caixa térmica (isopor) e encaminhado ao laboratório de Tecnologia de Aplicação de Defensivos Agrícolas para a remoção do marcador e posterior medição da área foliar de cada planta em um medidor de área foliar de bancada LICOR, modelo LI-3100.

Em cada saco plástico, foram colocados $20 \mathrm{~mL}$ de água destilada e procedeu-se a agitação por 30 segundos visando a remoção do corante das plantas alvo. A solução de lavagem foi colocada em potes plásticos com capacidade de $50 \mathrm{~mL}$ e tampa de rosca, os quais foram mantidos à $8 \pm 3^{\circ} \mathrm{C}$ até o momento da análise.

As leituras (absorbância) dos depósitos do marcador na solução de lavagem foram realizadas em espectrofotômetro UV - VIS, Shimadzu, modelo CP 1601, equipado com filtro no comprimento de onda de 630 nanômetros $(\mathrm{nm})$, conforme método descrito por Palladini et al. (2005).

Para determinação da concentração $\left(\mathrm{mg} \mathrm{L}^{-1}\right)$ dos depósitos foi confeccionada a curva padrão de linearidade com a mesma solução aplicada a campo. A curva padrão de determinação da concentração do marcador na solução aplicada a campo foi determinada com modelo de regressão linear descrita como se segue:

$\mathrm{Abs}=\mathrm{Abs}$ água $+\mathrm{a} \times \mathrm{C}$

onde, $\mathrm{Abs}=$ valor de leitura de absorbância; Abs água = valor de leitura de absorbância da água; $\mathrm{a}=$ coeficiente angular; e, $\mathrm{C}=$ concentração.

Portanto, a concentração (C) do produto depositado pode ser apresentado conforme a seguinte equação:

$$
\mathrm{C}=\frac{(\text { Abs }- \text { Abs água })}{\mathrm{a}}
$$

Ao considerar que a concentração de corante Azul Brilhante na calda aplicada a campo foi de $1500 \mathrm{mg} \mathrm{L}^{-1}$ para a transformação dos depósitos em microlitro $(\mu 1)$ foi utilizado a seguinte equação.

$$
\mathrm{C}_{\mathrm{i}} \cdot \mathrm{V}_{\mathrm{i}}=\mathrm{C}_{\mathrm{f}} \cdot \mathrm{V}_{\mathrm{f}}
$$

onde, $\mathrm{C}_{\mathrm{i}}=$ concentração inicial do marcador na calda $\left(\mathrm{mg} \mathrm{L} \mathrm{L}^{-1}\right) ; \mathrm{V}_{\mathrm{i}}=$ volume retido pelo alvo $(\mu \mathrm{L}) ; \mathrm{C}_{\mathrm{f}}=$ concentração detectada em densidade óptica $\left(\mathrm{mg} \mathrm{L}^{-1}\right)$; $\mathrm{V}_{\mathrm{f}}=$ volume de diluição da amostra de cada planta $(\mu \mathrm{L})$.

\section{Resultados e Discussão}

Nas áreas da Agricultura e Cascalheira não houve influência da velocidade do ar sobre os depósitos da calda na planta (Tabelas 2 e 3, respectivamente), independente da época de pulverização (53 e 67 DAS). Na Tabela 4 observa-se nenhuma diferença significativa aos 53 DAS, entre os depósitos da pulverização de plantas tratadas com diferentes técnicas de pulverização (Tabela 4). Para os volumes de calda retidos na planta de trigo, somente houve influência desse fator com a pulverização realizada aos 53 DAS, com maiores depósitos para a pulverização realizada a $200 \mathrm{~L} \mathrm{ha}^{-1} \mathrm{em}$ relação ao volume de $100 \mathrm{~L} \mathrm{ha}^{-1}$. Maiores volumes proporcionam maiores depósitos na mesma velocidade de aplicação, no entanto, os depósitos nas plantas-alvo não dependem apenas do equipamento aplicador, mas também da idade, do tipo da cultura, densidade, condição operacional e do tipo de ponta de pulverização (SARIET et al, 2014).

\begin{tabular}{|c|c|c|c|c|}
\hline \multirow{3}{*}{$\begin{array}{l}\text { Velocidade do } \mathrm{Ar} \\
\left(\mathrm{km} \mathrm{h}^{-1}\right)\end{array}$} & \multicolumn{4}{|c|}{ Volume de calda $\left(\mathrm{L} \mathrm{ha}^{-1}\right)$} \\
\hline & \multicolumn{2}{|c|}{53 DAS $\left(\mu \mathrm{L} \mathrm{cm}^{-2}\right)$} & \multicolumn{2}{|c|}{67 DAS $\left(\mu \mathrm{L} \mathrm{cm}^{-2}\right)$} \\
\hline & 100 & 200 & 100 & 200 \\
\hline 0 & $0,2294 \mathrm{aA}$ & $0,4035 \mathrm{bA}$ & $0,2385 \mathrm{aA}$ & $0,2989 \mathrm{aA}$ \\
\hline 15 & $0,2645 \mathrm{aA}$ & $0,5132 \mathrm{bA}$ & $0,2412 \mathrm{aA}$ & $0,3231 \mathrm{aA}$ \\
\hline 29 & $0,3091 \mathrm{aA}$ & $0,5152 \mathrm{bA}$ & $0,2969 \mathrm{aA}$ & $0,3368 \mathrm{aA}$ \\
\hline $\mathrm{CV} \%$ & & & & \\
\hline DMS Volume & & & & \\
\hline DMS Velocidade & & & & \\
\hline
\end{tabular}

Tabela 2. Média dos depósitos da pulverização aos 53 e 67 dias após a semeadura, na Área da Agricultura.

Médias seguidas de mesma letra, minúscula na linha e maiúscula na coluna, não diferem significativamente entre si, pelo teste de Tukey (p $\leq 0,05)$. 
Tabela 3.Média dos depósitos da pulverização aos 53 e 67 dias após a semeadura, na Área da Cascalheira.

\begin{tabular}{|c|c|c|c|c|}
\hline \multirow{3}{*}{$\begin{array}{c}\text { Velocidade } \\
\text { do } \operatorname{Ar}\left(\mathrm{km} \mathrm{h}^{-1}\right)\end{array}$} & \multicolumn{4}{|c|}{ Volume de calda $\left(\mathrm{L} \mathrm{ha}^{-1}\right)$} \\
\hline & \multicolumn{2}{|c|}{53 DAS $\left(\mu \mathrm{L} \mathrm{cm}^{-2}\right)$} & \multicolumn{2}{|c|}{67 DAS $\left(\mu \mathrm{L} \mathrm{cm}^{-2}\right)$} \\
\hline & 100 & 200 & 100 & 200 \\
\hline 0 & $0,2217 \mathrm{aA}$ & $0,3454 \mathrm{bA}$ & $0,2242 \mathrm{aA}$ & $0,4200 \mathrm{bA}$ \\
\hline 15 & $0,2450 \mathrm{aA}$ & $0,3613 \mathrm{bA}$ & $0,2583 \mathrm{aA}$ & $0,4291 \mathrm{bA}$ \\
\hline 29 & $0,2790 \mathrm{aA}$ & $0,4069 \mathrm{bA}$ & $0,2661 \mathrm{aA}$ & $0,4825 \mathrm{bA}$ \\
\hline CV \% & \multicolumn{2}{|c|}{14,08} & \multicolumn{2}{|c|}{14,69} \\
\hline DMS Volume & \multicolumn{2}{|c|}{0,06} & \multicolumn{2}{|c|}{0,07} \\
\hline DMS Velocidade & \multicolumn{2}{|c|}{0,07} & \multicolumn{2}{|c|}{0,09} \\
\hline
\end{tabular}

Médias seguidas de mesma letra, minúscula na linha e maiúscula na coluna, não diferem significativamente entre sí, pelo teste de Tukey (p $\leq 0,05)$.

Tabela 4. Média dos depósitos da pulverização aos 53 e 67 Dias Após a Semeadura, na Área da Agricultura

\begin{tabular}{|c|c|c|c|c|}
\hline \multirow{3}{*}{$\begin{array}{l}\text { Velocidade } \\
\text { do } \operatorname{Ar}\left(\mathrm{km} \mathrm{h}^{-1}\right)\end{array}$} & \multicolumn{4}{|c|}{ Ângulo de Pulverização } \\
\hline & \multicolumn{2}{|c|}{53 DAS $\left(\mu \mathrm{L} \mathrm{cm}^{-2}\right)$} & \multicolumn{2}{|c|}{67 DAS $\left(\mu \mathrm{L} \mathrm{cm}^{-2}\right)$} \\
\hline & $0^{\circ}$ & $30^{\circ}$ & $0^{\circ}$ & $30^{\circ}$ \\
\hline 0 & $0,2107 \mathrm{aA}$ & $0,2763 \mathrm{aA}$ & $0,2552 \mathrm{aA}$ & $0,4531 \mathrm{bAB}$ \\
\hline 15 & $0,2759 \mathrm{aA}$ & $0,2243 \mathrm{aA}$ & $0,2823 \mathrm{aA}$ & $0,5362 \mathrm{bB}$ \\
\hline 29 & $0,2478 \mathrm{aA}$ & $0,2958 \mathrm{aA}$ & $0,2887 \mathrm{aA}$ & $0,4386 \mathrm{bA}$ \\
\hline $\mathrm{CV} \%$ & \multicolumn{2}{|c|}{26,15} & \multicolumn{2}{|c|}{12,75} \\
\hline DMS Volume & \multicolumn{2}{|c|}{0,09} & \multicolumn{2}{|c|}{0,07} \\
\hline DMS Velocidade & \multicolumn{2}{|c|}{0,12} & \multicolumn{2}{|c|}{0,08} \\
\hline
\end{tabular}

A necessidade de redução de custos operacionais e aumento da rapidez do tratamento utilizando-se volumes de aplicação cada vez menores, traz o desenvolvimento de novas tecnologias. O volume de calda depende do tipo de aplicação a ser realizado, das características do alvo e das condições ambientais. Observando-se o efeito do volume de aplicação com ponta de jato plano sobre a cobertura de alvos planos, nota-se um aumento significativo de cobertura quando o volume de aplicação utilizado passou de 100 para $200 \mathrm{~L} \mathrm{ha}^{-1}$.

Não houve diferença dos resultados obtidos na deposição da pulverização utilizando-se diferentes volumes (100 e $200 \mathrm{~L} \mathrm{ha}^{-1}$ ) aos 67 DAS. Tal fato pode ser devido à arquitetura da planta, pois aos 67 DAS a planta de trigo encontrava-se com maior índice de área foliar e porte maior (altura média de $62,2 \mathrm{~cm}$ ), quando comparado aos 53 DAS (altura média de 35, $26 \mathrm{~cm}$ ), obtendo-se maior penetração da pulverização nas plantas de trigo, facilitando o controle.

Dados semelhantes foram encontrados por Gulart et al (2013), que observaram o "efeito guarda-chuva", onde as gotas tem maior barreira foliar, dificultando a aplicação do produto em todas as folhas das plantas, não atingindo o alvo por completo.

Apesar de não haver diferença significativa entre os tratamentos, verificou-se que quanto maior o volume de calda utilizado na pulverização e velocidade do ar na barra de pulverização, maiores foram os valores de depósitos nas plantas de trigo, tanto para 53 DAS quanto para $67 \mathrm{DAS}$.
$\mathrm{Na}$ área Cascalheira, para avaliação realizada nos respectivos volumes de calda, observa-se aos 53 e 67 DAS maiores depósitos quando a pulverização foi realizada à $200 \mathrm{~L} \mathrm{ha}^{-1}$ em relação ao volume de $100 \mathrm{~L}$ $\mathrm{ha}^{-1}$; valores estes que corroboram com a Tabela 2, referente aos resultados obtidos na Área da Agricultura.

Pode-se verificar que não houve diferença significativa, aos 53 DAS entre os depósitos da pulverização de plantas tratadas com diferentes técnicas de pulverização (Tabela 4). Aos 67 DAS, com ângulo na barra de pulverização a $30^{\circ}$ houve incremento dos depósitos da pulverização nas diferentes velocidades de ar junto a barra de pulverização, especialmente com a velocidade de ar $15 \mathrm{~km} \mathrm{~h}^{-1}$ obtendo-se depósitos superiores.

A angulação dos jatos de pulverização, combinada ao uso da assistência de ar podem otimizar os níveis dos depósitos da pulverização nas plantas, principalmente na parte inferior, onde com o auxílio do vento um maior espaço entre as folhas é alcançado evitando o efeito "guarda-chuva", proporcionando melhor controle das doenças (CHRISTOVAM et al., 2010).

A arquitetura, o estádio de desenvolvimento das plantas, velocidade do ar, volume de aplicação e tamanho das gotas podem influenciar significativamente os níveis dos depósitos da pulverização, por isso devem ser avaliados para se obter sucesso nos controles.

As análises de variâncias do depósito de gotas de pulverização na junção de velocidade do ar e com diferentes ângulos de posicionamento das pontas de 
aplicação em relação à cultura, estão dispostas na Tabela 5.

Para o experimento realizado na área da Cascalheira, após a realização das análises não foi observada nenhuma diferença significativa, aos 53 e 67 DAS, entre os depósitos da pulverização em plantas tratadas com as diferentes técnicas de pulverização. Isto evidencia que não houve efeito da assistência de ar ou tampouco do ângulo da barra de pulverização sobre os níveis dos depósitos em plantas de trigo Tabela 6 .

Tabela 5. Análise de variância dos depósitos da pulverização (Velocidade do Ar x Ângulo) aos 53 e 67 DAS na área da Agricultura e Cascalheira

\begin{tabular}{|c|c|c|c|}
\hline \multirow{2}{*}{ Fator de Variação } & \multirow{2}{*}{ G.L } & 53 DAS & 67 DAS \\
\hline & & $\mathrm{Pr}>\mathrm{Fc}$ & $\operatorname{Pr}>\mathrm{Fc}$ \\
\hline & & \multicolumn{2}{|c|}{ Área de Agricultura } \\
\hline Velocidade & 2 & $0,6800 \mathrm{NS}$ & $0,0738 \mathrm{NS}$ \\
\hline Ângulo & 1 & $0,4571 \mathrm{NS}$ & $0,0000 *$ \\
\hline Veloc. x Ângulo & 2 & $0,1947 \mathrm{NS}$ & $0,1229 \mathrm{NS}$ \\
\hline Erro & 18 & & \\
\hline Total corrigido & 23 & & \\
\hline $\mathrm{CV} \%$ & & 26,15 & 12,75 \\
\hline \multirow[t]{2}{*}{ Média geral } & & 0,2551 & 0,38 \\
\hline & & \multicolumn{2}{|c|}{ Área de Cascalheira } \\
\hline Velocidade & 2 & $0,4142 \mathrm{NS}$ & $0,7107 \mathrm{NS}$ \\
\hline Ângulo & 1 & $0,4763 \mathrm{NS}$ & $0,2277 \mathrm{NS}$ \\
\hline Veloc. x Ângulo & 2 & $0,4536 \mathrm{NS}$ & $0,6931 \mathrm{NS}$ \\
\hline Erro & 18 & & \\
\hline Total corrigido & 23 & & \\
\hline CV\% & & 13,34 & 22,71 \\
\hline Média geral & & 0,2419 & 0,2754 \\
\hline
\end{tabular}

Tabela 6. Média dos depósitos da pulverização (53 e 67 DAS) na Área da Cascalheira.

\begin{tabular}{|c|c|c|c|c|}
\hline \multirow{3}{*}{$\begin{array}{c}\text { Velocidade } \\
\text { do } \operatorname{Ar}\left(\mathrm{km} \mathrm{h}^{-1}\right)\end{array}$} & \multicolumn{4}{|c|}{ Ângulo da Barra de Pulverização } \\
\hline & \multicolumn{2}{|c|}{53 DAS $\left(\mu \mathrm{L} \mathrm{cm}^{-2}\right)$} & \multicolumn{2}{|c|}{67 DAS $\left(\mu \mathrm{L} \mathrm{cm}^{-2}\right)$} \\
\hline & $0^{\circ}$ & $30^{\circ}$ & $0^{\circ}$ & $30^{\circ}$ \\
\hline 0 & $0,2349 \mathrm{aA}$ & $0,2252 \mathrm{aA}$ & $0,2719 \mathrm{aA}$ & $0,2734 \mathrm{aA}$ \\
\hline 15 & $0,2404 \mathrm{aA}$ & $0,2475 \mathrm{aA}$ & $0,2372 \mathrm{aA}$ & $0,2905 \mathrm{aA}$ \\
\hline 29 & $0,2360 \mathrm{aA}$ & $0,2675 \mathrm{aA}$ & $0,2691 \mathrm{aA}$ & $0,3099 \mathrm{aA}$ \\
\hline $\mathrm{CV} \%$ & \multicolumn{2}{|c|}{13,34} & \multicolumn{2}{|c|}{22,71} \\
\hline DMS Ângulo & \multicolumn{2}{|c|}{0,04} & \multicolumn{2}{|c|}{0,09} \\
\hline DMS Velocidade & \multicolumn{2}{|c|}{0,05} & \multicolumn{2}{|c|}{0,11} \\
\hline
\end{tabular}

Médias seguidas de mesma letra, minúscula na linha e maiúscula na coluna, não diferem significativamente entre sí, pelo teste de Tukey $(\mathrm{p} \leq 0,05)$.

\section{Conclusões}

Para se alcançar maior produção, o controle das pragas e doenças deve ser realizado de maneira eficiente e com menor custo ao produtor. O uso de tecnologia nas aplicações se torna cada vez mais necessário e comum para que se alcance o alvo desejável.

Verifica-se que o controle curativo das doenças é possível desde que se utilize a melhor forma para a aplicação. Deve se considerar o desenvolvimento da planta, realizando-se aplicações no momento correto e melhores equipamentos que se destaquem no controle, diminuindo as perdas de produção.

$\mathrm{O}$ volume de calda que alcançou um melhor desempenho na deposição de gotas foi $200 \mathrm{~L} \mathrm{~h}^{-1}$, tendo como adicional a cortina de ar uma melhor deposição. Combinado volume de calda e inserção de ar juntamente com uma angulação da ponta de pulverização observase maior deposição dos produtos no alvo.

\section{Referências Bibliográficas}

CHRISTOVAM, R. S.; RAETANO, C. G.; AGUIAR JUNIOR, H. O.; DAL-POGETTO, M. H. A.; PRADO, E. P.; GIMENES, M. J.; KUNZ, V. L. Assistência de Ar em Barra Pulverização no Controle de Ferrugem Asiática na Soja, Bragantia, Campinas-SP, v. 69, n. 1, p. 231-238, 2010.

FIALLOS, F. R. G.; BOLLER, W.; FERREIRA, M. C.; DURÃO, C. F. Eficiência de fungicidas no controle de doenças foliares na cultura do trigo, em resposta à aplicação com diferentes pontas de pulverização, Scientia Agropecuaria, Trujillo - Peru, v. 2, n. 4, p. 229 - 237, 2011.

GULART, C. A.; DEBORTOLI, M.; MADALOSO, M.; BALARDIN, R.; SANTOS, P. S.; CORTE, G. D.; LENS, G.; MARQUES, L. N. Espectro de Gotas de Pulverização e Controle de Doenças em duas Cultivares de Trigo, Ciência Rural, Santa Maria-RS, v. 43, n. 10, p. 1747-1753, 2013.

NAVARINI, L.; BALARDIN, R.S. Doenças foliares e o controle por fungicidas na produtividade e qualidade de grãos 
de trigo. Summa Phytopathologica, Botucatu-SP, v. 38, n. 4, p. 294-299, 2012.

PALlADINI, L. A.; RAETANO, C. G.; VELINI, E. D. Choice of tracers for the evaluation of spray deposits.ScientiaAgricola, Piracicaba-SP, v. 62, n. 5, p. 440445,2005

SANTOS, H. A. A.; PRIA, M. D.; SILVA, O. C.; MIO, L. L. M. Controle de doenças do trigo com fosfitos e acibenzolar-smetil isoladamente ou associados apiraclostrobina + epoxiconazole: Ciências Agrárias, Londrina-PR, v. 32, n. 2, p. 433-442, 2011.
SARI, B. G.; STEFANELO, M. S.; LENZ, G.; COSTA, I. F. D.; ARRUÉ, A.; AUGUSTI, G. R.; PES, M. P. Controle de Doenças Foliares em Trigo com Equipamentos de Pulverização de Baixo Volume de Aplicação. Ciência Rural, Santa Maria-RS, v. 44, n. 11, p. 1966-1972, 2014. 